\title{
CRESCIMENTO DE CULTIVARES DE FEIJÃO SOB INTERFERÊNCIA DE TRAPOERABA
}

\author{
Lidiane dos Santos Gomes Oliveira ${ }^{1}$ \\ Amanda Costa ${ }^{2}$ \\ Clever Geraldo Coelho ${ }^{3}$ \\ Ludimila Pimenta Alves Fernandes ${ }^{4}$ \\ Leandro Pin Dalvi ${ }^{5}$
}

Resumo: O feijão comum (Phaseolus vulgaris L.) apresenta alterações na produtividade de grãos com interferência de plantas daninhas e também relacionada ao vigor das sementes utilizadas para plantio da cultura. O trabalho tem como objetivo avaliar o vigor das sementes sob competição com trapoeraba. $O$ experimento foi conduzido em casa de vegetação, avaliando massa fresca total, comprimento do caule, massa fresca da raiz, massa fresca da parte aérea, massa seca total, massa seca do caule, massa seca da raiz e a massa seca parte aérea. Os resultados obtidos permitem constatar que o grau de interferência variou conforme o lote, a cultivar, e o tratamento. Foi concluído que sementes oriundas do lote 2013, apresentaram plantas mais vigorosas e realocaram maior biomassa para parte aérea quando submetidas à competição.

Palavras-chave: Commelina diffusa L.; Competição; Phaseolus vulgaris L.; Partição de massa.

\footnotetext{
1 Programa de Pós Graduação em Genética e Melhoramento de Planta / Universidade Federal do Espírito Santo(CCAE), Brasil. E-mail: lidianegomes31@gmail.com.

2 Programa de Pós Graduação em Agricultura Tropical / Universidade Federal do Espírito Santo(CEUNES), Brasil. E-mail: amandabissoly@hotmail.com.

3 Programa de Pós Graduação em Genética e Melhoramento de Planta / Universidade Federal do Espírito Santo(CCAE), Brasil. E-mail: clevercoelho2010@hotmail.com.

4 Programa de Pós Graduação em Genética e Melhoramento de Planta / Universidade Federal do Espírito Santo(CCAE), Brasil. E-mail: ludi_pimentalu@hotmail.com.

${ }^{5}$ Professor Departamento de Produção Vegetal/ Universidade Federal do Espírito Santo (CCAE), Brasil. E-mail: leandropin@yahoo.com.br.
} 